\title{
Design of control system for driverless tractor
}

\author{
Yibo $\mathrm{Li}^{1}$, Qi $\mathrm{Cao}^{1, *}$, and Fang $\mathrm{Liu}^{1}$ \\ ${ }^{1}$ China, Liaoning, Shenyang Aerospace University
}

Keywords: Unmanned agricultural machinery, path tracking, RTK-GPS.

\begin{abstract}
This paper uses Tianjin TieNiu crawler tractor as the experimental platform to design an unmanned agricultural machinery control system based on RTK-GPS (Differential GPS Technology). The article expounds the overall design of the control system and proposes a path tracking control algorithm. Simulation and experimental results show that the control algorithm can complete the path tracking requirements of unmanned agricultural machinery. The system can control the unmanned agricultural machinery to follow a predetermined route. The speed is $0.55 \mathrm{~m} / \mathrm{s}$, the maximum error of linear path tracking of agricultural machinery is $4.09 \mathrm{~cm}$, the average error is $2.20 \mathrm{~cm}$, the maximum error of large diameter circular path tracking is $20.67 \mathrm{~cm}$, the average error is $8.34 \mathrm{~cm}$, and the maximum error of continuous small diameter turning path tracking is $23.14 \mathrm{~cm}$, the average error is $7.38 \mathrm{~cm}$, both meet the operational requirements.
\end{abstract}

\section{Introduction}

Since the 1990s, developed countries in Europe and the United States have carried out research on the "precise agriculture" technology system. Agricultural vehicle automatic navigation technology is an important branch of precision agriculture, and obtaining high-precision positioning solution is the basis for automatic navigation of farmland vehicles $^{[1]}$. Realizing the intelligent navigation of agricultural machinery can effectively improve the accuracy of field operations. In recent years, a lot of research has been done on the automatic driving technology of agricultural machinery at home and abroad.

Kim et al. ${ }^{[2]}$ established a dynamic model of agricultural machinery and TCP/IP communication protocol, developed a path tracking simulator and used the Tongyang TX803 tractor equipped with RTK-GPS receiver and steering controller for driving test. Nagasaka et $\mathrm{al}^{[3]}$ developed an automatic rice transplanter based on global positioning system and inertial measurement unit. After 12 linear operations, the rms lateral deviation is less than $0.04 \mathrm{~m}$, and the rms heading angle error is less than 3.6 degrees. Li Yongjian et al. ${ }^{[4,5]}$ designed an automatic navigation system based on RTK-DGPS positioning and double closed-loop steering control based on Dongfanghong X-804 tractor. Shi Yangjie et al. ${ }^{[6]}$ proposed the GNSS/INS/vehicle integrated navigation method, which effectively reduced the accuracy requirements of the inertial measurement unit, and the agricultural

\footnotetext{
*Corresponding author:851434033@qq.com
} 
machine operation results met the standard requirements. For the path tracking control algorithm, modern control theory and method such as adaptive control, artificial neural network, fuzzy control and synovial control are used ${ }^{[7]}$. Alexey et al. ${ }^{[8]}$ proposed a path tracking control algorithm based on a pure sliding mode controller to constrain the steering angle of the vehicle body and ensure that the path of arbitrary bending is tracked. The sliding mode method and the smooth nonlinear control law are used to effectively improve the jitter generated in the control. Zhang $\mathrm{Wei}^{[9]}$ constructed a pure tracking model, combined with the idea of neural fuzzy control (ANFIS), designed a forward-distance adaptive autonomous following algorithm based on ANFIS. Fuzzy control has become a mainstream trend and is often used in path tracking control in recent years. In order to improve the stability and robustness of agricultural machinery path tracking control under different speed conditions, experts and scholars combined fuzzy control with other intelligent control to design a variety of intelligent control methods, and verified the feasibility of the method through experiments ${ }^{[10,11,12]}$.

This paper mainly introduces the overall structural design of unmanned agricultural machinery, which is divided into two parts: hardware design and software design. The hardware design includes mechanical design and circuit design. Software design includes control system execution process programming and path tracking control algorithms. By comparing the traditional PID control, fuzzy control and fuzzy PID control, this paper selects the fuzzy PID control algorithm to control the agricultural machinery steering, and selects the traditional incremental PID control algorithm to control the speed of the vehicle body during the traveling process. The automatic control system based on RTK-GPS and electronically controlled hydraulic steering was developed on Tianjin Tieniu crawler tractor to realize high-precision steering control of unmanned agricultural machinery, reduce control overshoot and improve the navigation precision of agricultural machinery in the field. After experimental verification, when the speed is $0.55 \mathrm{~m} / \mathrm{s}$, the maximum error of linear path tracking of agricultural machinery is $4.09 \mathrm{~cm}$, the average error is $2.20 \mathrm{~cm}$, the maximum error of large diameter circular path tracking is $20.67 \mathrm{~cm}$, the average error is $8.34 \mathrm{~cm}$, continuous small diameter turning The path tracking maximum error is $23.14 \mathrm{~cm}$, and the average error is $7.38 \mathrm{~cm}$, which meets the operation requirements.

\section{The overall design of the unmanned agricultural machinery control system}

This design uses STM32F103 as the main control chip, realizes data communication between SMT32 and RTK-GPS navigation module through its own serial port 3, serial port 4 realizes data communication between STM32 and host computer software, serial port 5 realizes STM32 and obstacle avoidance module communication. Through the STM32's timer output, the 3-way PWM square wave controls the steering gear and the electric push rod to drive the actuator, and captures the six channels of the remote control to remotely control the agricultural machine. The electromechanical transformation of the throttle and gear lever is mainly to replace the shift lever action by the steering wheel of the steering gear, thereby controlling the operation of the agricultural machinery actuator by outputting PWM waves. The control algorithm uses the combination of traditional incremental PID control and fuzzy PID control to control the throttle lever and gear shift lever of the agricultural machinery, thereby adjusting the speed and angle during the operation of the agricultural machine, so that the corresponding path tracking action is completed. . The overall structure is shown in Figure 1.

The steering control system designed in this paper replaces the cable structure shown in Figure 2 with the MG996R high-torque steering gear based on the original steering system. 
At the same time, the steering mechanism is controlled by the on-off control steering gear of the relay group.

The main working mode of the steering system is: STM32F103 controller receives the latitude, longitude and latitude and longitude data of RTK module real-time transmission through serial communication mode, calculates the real-time target angle, compares the current heading angle with the target angle, and passes fuzzy PID control. The output corresponds to the pulse value of the PWM signal to control the steering gear, thereby controlling the steering of the vehicle body.

The throttle and the gear control mechanical structure are similar. The left side of Figure 3 is the throttle throttle control mechanism before the vehicle is modified. The pull-wire structure is controlled by the push-pull lever to control the change of the throttle and gear position of the vehicle body. The right part of Figure 3 is the modified structure. The structure of the cable is controlled by a large torque steering gear instead of the manual controlled push-pull process.

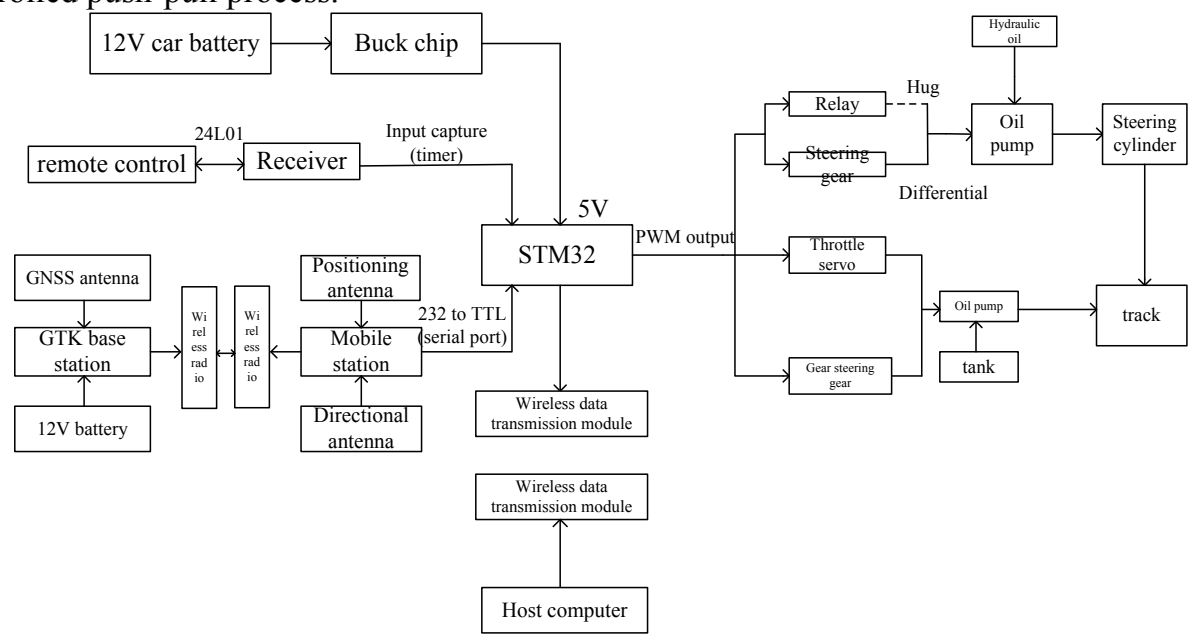

Fig. 1. Control system structure.

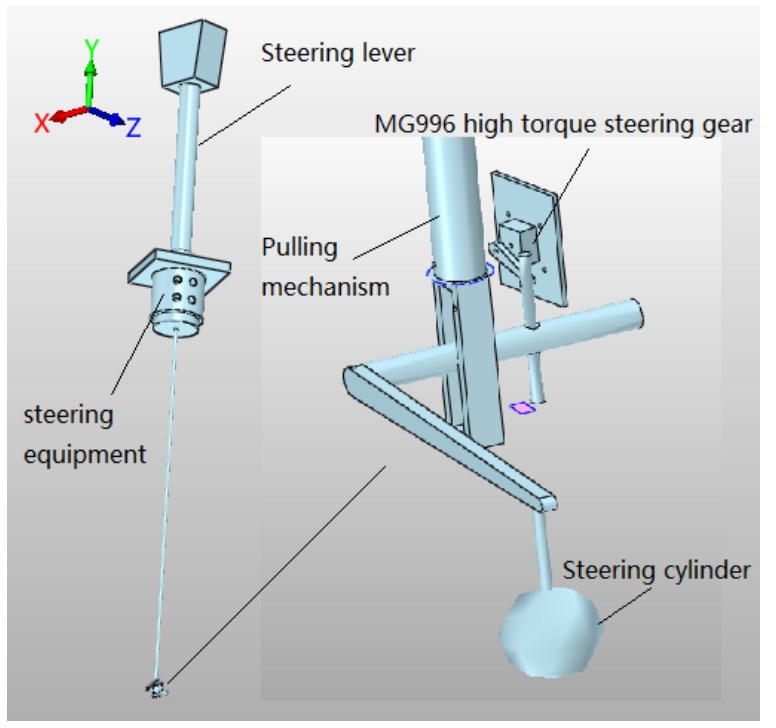

Fig. 2. Steering control mechanism. 


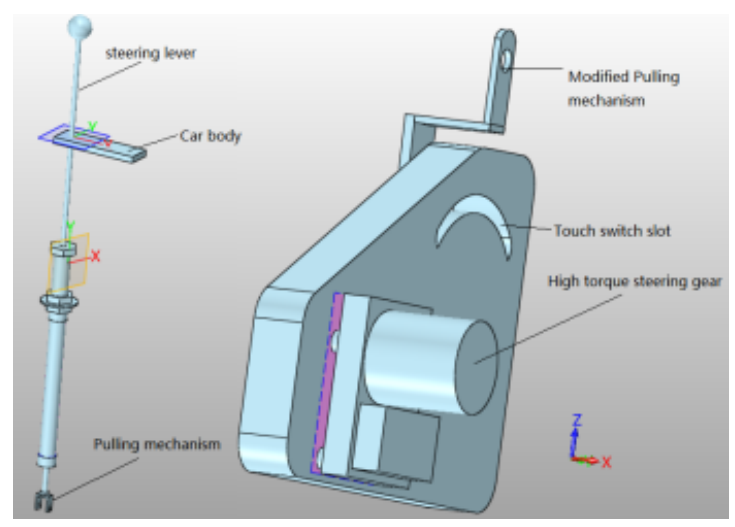

Fig. 3. Throttle and gear position control mechanism.

\section{Hardware circuit design of unmanned agricultural machinery control system}

This design takes STM32F103 as the main control unit, and supplies voltage to the stm32 by adding a buck chip to the $12 \mathrm{~V}$ car battery. Control is divided into manual control and automatic control. Manually control the input capture of the remote control receiver through the timer of the STM32, and then control the action of the actuator through the timer output pwm wave. Manual and automatic switching is achieved in the circuit by controlling the on and off of the relay. The automatic control transmits the target position information to the lower computer through the serial port transmission mode through the host computer. During the period, the signal is correspondingly converted by the RS232 to TTL module, and the lower computer receives the attitude information of the real-time transmission of the RTK-GPS, and continuously performs the posture information on the actuator. Adjustment, so that the unmanned agricultural machine completes the path tracking control.

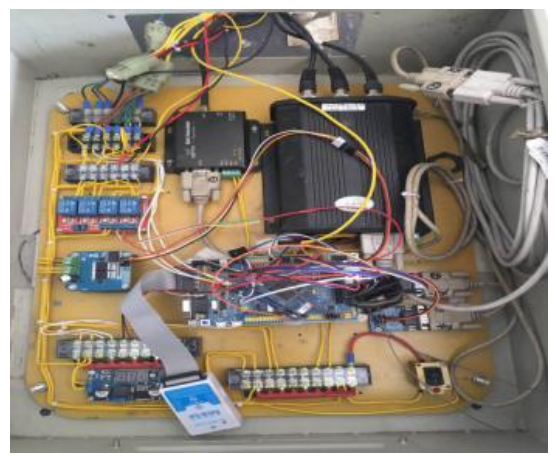

Fig. 4. Control system hardware physical map.

\section{Control system software design}

\subsection{Communication process between host computer and lower computer}

When the control mode is automatic mode, the upper computer and the lower computer communicate through the wireless data transmission module, and the baud rate is 9600 . The 
host computer sends the initialization information and the target point information, and the lower position machine successfully performs the path tracking control.

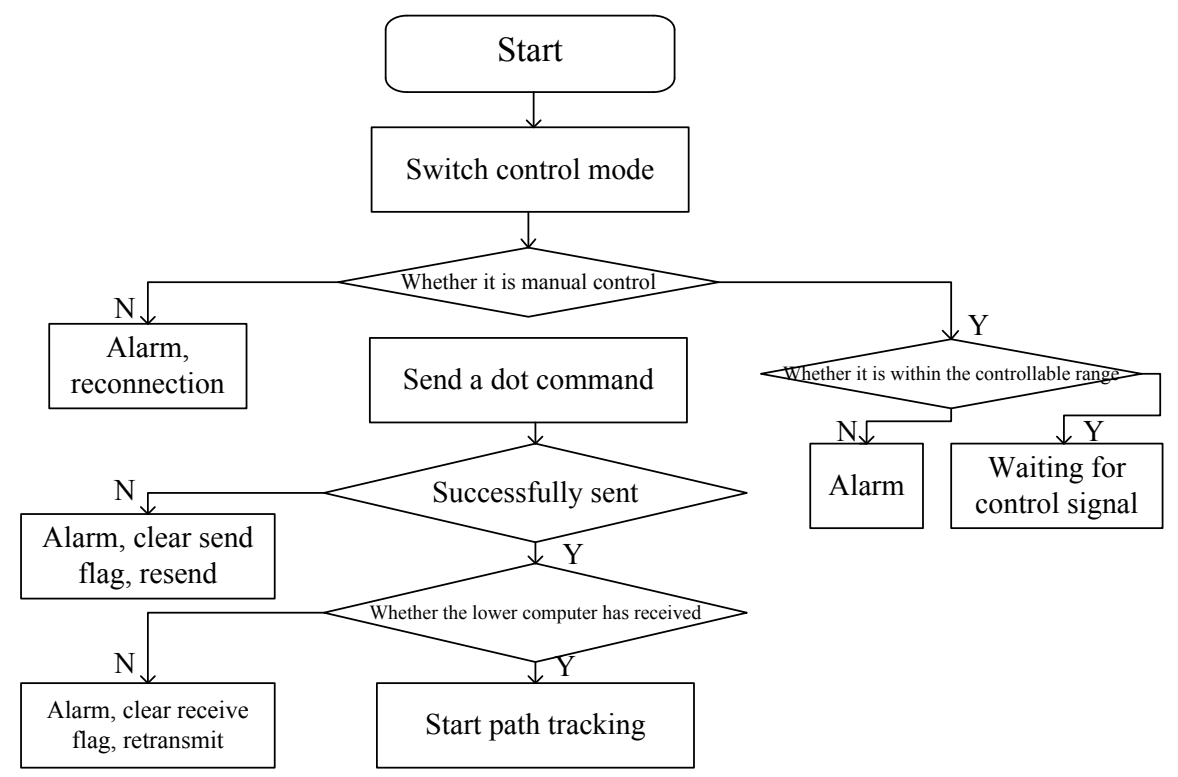

Fig. 5. Communication flowchart between upper computer and lower computer.

\subsection{Path tracking process}

After the path tracking starts, the program continuously verifies whether the conditions that have reached the target point are met. When the condition is met, it is judged whether the vehicle has reached the end point, and if it is not reached, it continues to advance to the new target point. When the angle is within a certain range, the gear controller and the throttle are controlled by the PID controller output increment, and the vehicle runs at a differential speed. If the angle is larger than the specified range, the car body will be locked and turned until it reaches the angle range, and the differential advance will be continued and the vehicle body will be adjusted at a small angle. At the end of the journey, the vehicle stops. 


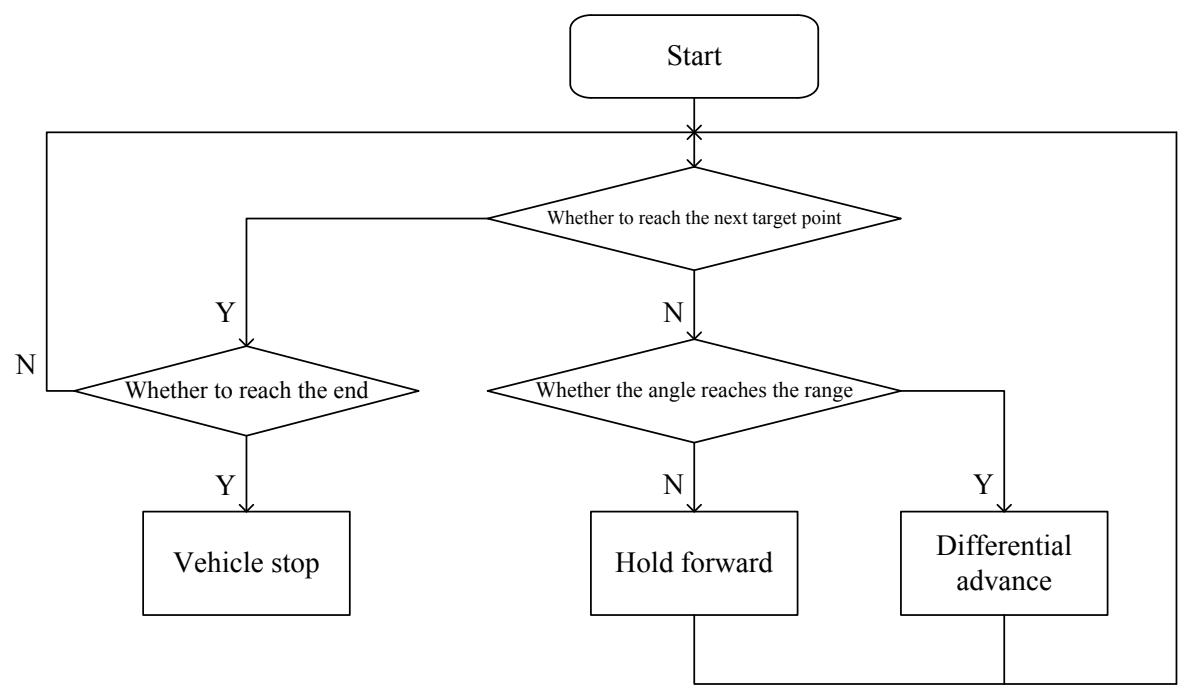

Fig. 6. Path tracking flowchart.

\subsection{Path tracking control algorithm}

The control algorithm plays a crucial role in the overall steering control system. In this paper, the fuzzy PID control algorithm is used, as shown in Figure 7. The deviation E between the target angle and the feedback angle and the difference Ec between the current period deviation and the previous period deviation are taken as the input variables of the two-dimensional fuzzy controller, and the PID parameters are changed. The quantity is used as the output variable of the two-dimensional fuzzy controller. The PID parameters are adjusted online by the fuzzy controller, and the PID parameter variation is output, so that the PID parameters are adjusted in real time. The difference between the actual heading and the target heading is calculated as the input of the incremental PID controller, and the PID controller outputs the angle increment. The increment is used as the input of the main controller, and the controller output corresponds to the signal amount used to control the throttle and the gear position after the input is solved, thereby controlling the action of the actuator to achieve the purpose of path tracking.

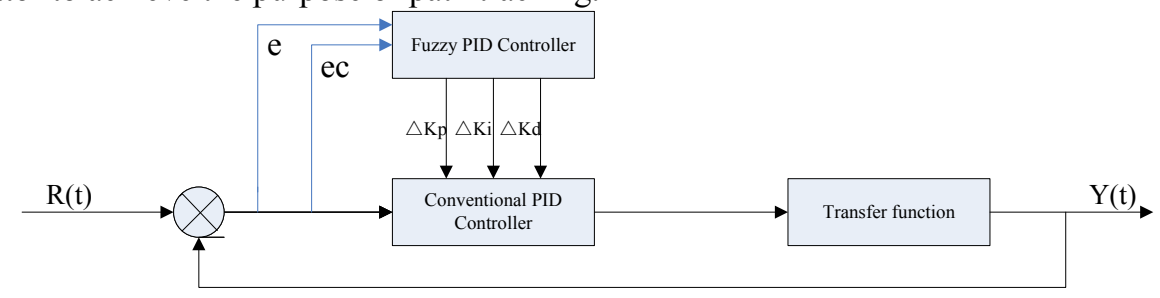

Fig. 7. Block diagram of the adaptive fuzzy PID control system. 


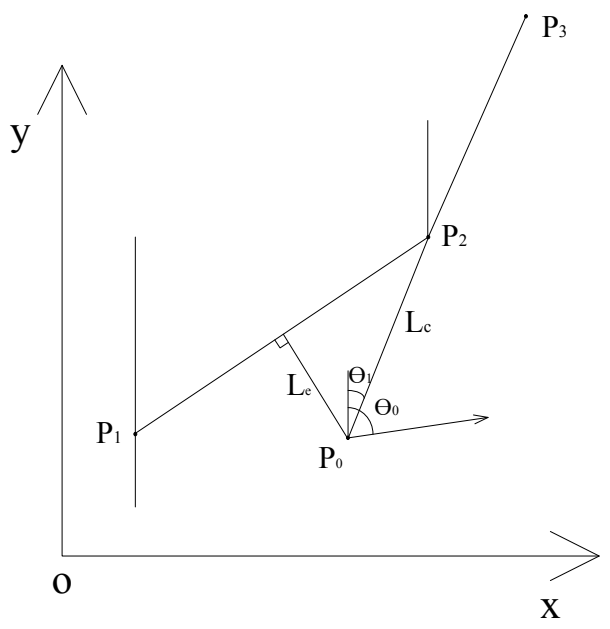

Fig. 8. Path tracking diagram.

As shown in Figure 8, it is known that the coordinates of three consecutive path task points on the predetermined path are $\mathrm{P}_{1}\left(\mathrm{X}_{1}, \mathrm{Y}_{1}\right), \mathrm{P}_{2}\left(\mathrm{X}_{2}, \mathrm{Y}_{2}\right)$ and $\mathrm{P}_{3}\left(\mathrm{X}_{3}, \mathrm{Y}_{3}\right)$, The current position coordinate point of the unmanned agricultural machine is $\mathrm{P}_{0}\left(\mathrm{X}_{0}, \mathrm{Y}_{0}\right)$. Calculate the distance of the agricultural machine from the current target point by calculation is $\mathrm{L}_{\mathrm{c}}$. Set the straight line expression of the current point of the farm machine and the current task point as $y=k^{*} x+b$. According to the coordinates of the $P_{0}$ and $P_{2}$ points, The values of angle $\theta_{1}$ and distance $\mathrm{L}_{\mathrm{c}}$ can be calculated as follows:

$$
\begin{aligned}
& \theta_{1}= \begin{cases}0 ; & x_{0}=x_{2}, y_{0}<y_{2} \\
360-\arctan \left(\left(\mathrm{x}_{0}-\mathrm{x}_{2}\right) /\left(\mathrm{y}_{2}-\mathrm{y}_{0}\right)\right) ; & x_{0}>x_{2}, y_{0}<y_{2} \\
90 ; \quad x_{0}<x_{2}, y_{0}=y_{2} & \\
180+\arctan \left(\left(\mathrm{x}_{0}-\mathrm{x}_{2}\right) /\left(\mathrm{y}_{0}-\mathrm{y}_{2}\right)\right) ; & \mathrm{x}_{0}>\mathrm{x}_{2}, \mathrm{y}_{0}>\mathrm{y}_{2} \\
180 ; \quad x_{0}=x_{2}, y_{0}>y_{2} & \\
90+\arctan \left(\left(\mathrm{y}_{0}-\mathrm{y}_{2}\right) /\left(\mathrm{x}_{2}-\mathrm{x}_{0}\right)\right) ; & x_{0}<x_{2}, y_{0}>y_{2} \\
270 ; \quad \mathrm{x}_{0}>\mathrm{x}_{2}, \mathrm{y}_{0}=\mathrm{y}_{2} & \\
\arctan \left(\left(\mathrm{x}_{2}-\mathrm{x}_{0}\right) /\left(\mathrm{y}_{2}-\mathrm{y}_{0}\right)\right) ; & \mathrm{x}_{0}<\mathrm{x}_{2}, \mathrm{y}_{0}<\mathrm{y}_{2}\end{cases} \\
& L_{c}=\sqrt{\left(x_{0}-x_{2}\right)^{2}+\left(y_{0}-y_{2}\right)^{2}}
\end{aligned}
$$

Find the angle $\theta_{1}$, and know the current unmanned agricultural machine travel angle $\theta_{0}$, then the unmanned agricultural machine direction angle deviation is $\theta_{2}$ : 


$$
\theta_{2}= \begin{cases}\theta_{1}-\theta_{0} ; & 0<\theta_{1}<180,0<\theta_{0}<\theta_{1} \\ \theta_{1}-\theta_{0} ; & 0<\theta_{1}<180, \theta_{1}<\theta_{0}<\theta_{1}+180 \\ 360-\theta_{0}+\theta_{1} ; & 0<\theta_{1}<180, \theta_{1}+180<\theta_{0}<360 \\ 360-\theta_{1}+\theta_{0} ; & 180<\theta_{1}<360,0<\theta_{0}<\theta_{1}-180 \\ \theta_{1}-\theta_{0} ; & 180<\theta_{1}<360, \theta_{1}-180<\theta_{0}<\theta_{1} \\ \theta_{1}-\theta_{0} ; & \theta_{1}<\theta_{0}<360\end{cases}
$$

Then there are:

$$
\begin{gathered}
E=\theta_{2} \\
E_{\mathrm{c}}=E-E_{1} \\
K_{e}=\frac{2 n}{E_{\max }} \\
K_{\mathrm{ec}}=\frac{2 \mathrm{~m}}{E_{c \max }}
\end{gathered}
$$

$\mathrm{E}$ is the deviation of the target angle from the feedback angle, Ec is the difference between the current period deviation and the previous period deviation; Ke, $\mathrm{Kec}$ is the quantization factor. The fuzzy rules are shown in Table 1.

Table 1. Fuzzy rule control table for $\Delta \mathrm{Kp}$ and $\Delta \mathrm{Ki}$.

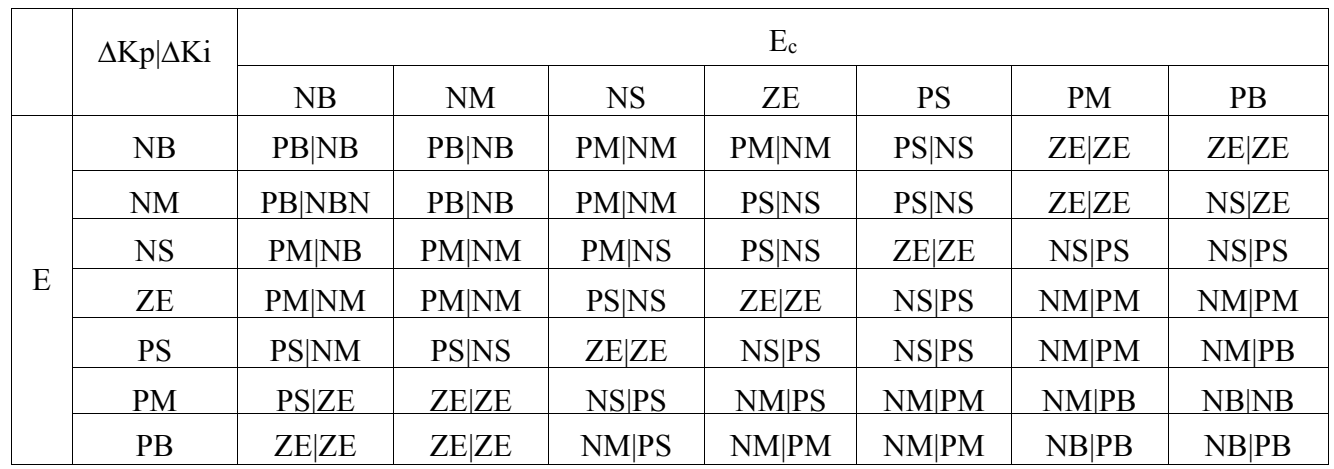

This design adopts the Mamdani fuzzy inference method. The parameters of the fuzzy rules are as follows:

rule1: if $(E$ is $N B)$ and ( $E_{c}$ is $\left.N B\right)$ then $\left(k_{p}\right.$ is $\left.P B\right)\left(k_{i}\right.$ is NB)

$\vdots$

rule49: if $(\mathrm{E}$ is $\mathrm{PB})$ and $\left(\mathrm{E}_{\mathrm{c}}\right.$ is $\left.\mathrm{PB}\right)$ then $\left(\mathrm{k}_{\mathrm{p}}\right.$ is $\left.\mathrm{NB}\right)\left(\mathrm{k}_{\mathrm{i}}\right.$ is $\left.\mathrm{PS}\right)$

Each fuzzy rule is as follows:

$$
\begin{aligned}
& \mu_{\Delta K P_{y}^{\prime}}(z)=\mu_{E_{i}}\left(E_{x}\right) \wedge \mu_{E c_{j}}\left(E_{y}\right) \wedge \mu_{\Delta K P_{y}}(z) \\
& =\min \left\{\mu_{\sim}^{\mu_{E_{i}}}\left(E_{x}\right), \mu_{E_{\sim}}\left(E_{y}\right), \mu_{\Delta K P_{y}}(z)\right\}, z=-6,-5, \ldots, 5,6
\end{aligned}
$$

Then the total fuzzy output is: 


$$
\begin{aligned}
& \Delta K P_{\gamma}=\bigcup_{\gamma=1}^{\mathrm{m} \times \mathrm{n}} \Delta K P_{\gamma}=\left\{\frac{\max _{\gamma=1}^{\mathrm{m} \times \mathrm{n}} \mu_{\Delta K P_{y}^{\prime}}(-6)}{-6}, \frac{\max _{\gamma=1}^{\mathrm{m} \times \mathrm{n}} \mu_{\Delta K P_{y}^{\prime}}(-5)}{-5}, \ldots \ldots, \frac{\max _{\gamma=1} \mu_{\Delta K P_{y}^{\prime}}(6)}{6}\right\} \\
& =\left\{\frac{\mu_{\Delta K P}(-6)}{-6}, \ldots, \frac{\mu_{\Delta K P}(6)}{6}\right\}
\end{aligned}
$$

This design uses a weighted average method to defuzzify:

$$
\mathrm{u}_{\mathrm{c}}=\frac{\left(\sum_{i=-s}^{s} i \cdot k_{i}\right)}{\left(\sum_{i=-s}^{s} k_{i}\right)}
$$

Then the actual control quantity $\Delta \mathrm{K}_{\mathrm{p}}, \Delta \mathrm{K}_{\mathrm{i}}$ is:

$$
\left\{\begin{array}{l}
\Delta K_{\mathrm{p}}=K_{\mathrm{pu}} \cdot \Delta K P \\
\Delta K_{\mathrm{i}}=K_{\mathrm{iu}} \cdot \Delta K I
\end{array}\right.
$$

$\mathrm{K}_{\mathrm{pu}}, \mathrm{K}_{\mathrm{iu}}$ is the scale factor. After fuzzy control, the parameters of the incremental PID are:

$$
\left\{\begin{array}{l}
K_{\mathrm{p}}=K_{\mathrm{p} 0}+\Delta K_{p} \\
K_{\mathrm{i}}=K_{\mathrm{i} 0}+\Delta K_{i}
\end{array}\right.
$$

where $K_{p 0}, K_{i 0}$ are the initial values of the incremental PID parameters. $\Delta K_{p}, \Delta K_{i}$ is the actual increment of the parameter output by the fuzzy controller. The direction angle deviation $\theta_{e}$ of the unmanned agricultural machine after PID control is calculated by the formula (4.14), where $K_{p}$ is the proportional coefficient, $K_{i}$ is the integral coefficient, and $\mathrm{K}_{\mathrm{d}}$ is the differential coefficient. In the design, $\mathrm{K}_{\mathrm{d}}=0, \mathrm{e}[0]=\theta_{2}$.

$$
\theta_{e}(t)=K_{p}\{e[n]-e[n-1]\}+K_{i} e[n]+K_{d}\{e[n]-2 e[n-1]+e[n-2]\}
$$

The angular increment value $\theta_{e}$ of the unmanned agricultural machine after being calculated by the intelligent PID controller is linearly superimposed with the signal amount of the current throttle gear of the unmanned agricultural machine, as a speed for controlling the unmanned agricultural machine to turn. The speed increment value of the unmanned agricultural machine after the operation of the separate incremental PID controller is linearly superimposed with the signal amount of the current throttle gear lever of the unmanned agricultural machine, as the speed for controlling the unmanned agricultural machinery to travel straight. 


\section{Experimental results and conclusions}

The path tracking test is performed on the ordinary lawn surface of the GPS navigation control system based on the iron cattle crawler tractor. The experiment stipulates that when the current angle of travel of the agricultural machine and the target angle difference is less than $7^{\circ}$, the agricultural machine adopts differential operation. On the contrary, the steering is performed by the lock mode, and after the angle difference reaches $7^{\circ}$ or less, the differential operation is continued. When Lc is within the specified range, the agricultural machine runs the next path until the last target point runs, and the agricultural machine stops.

Firstly, the path is planned by collecting GPS data, and then the sampling effect is manually determined. After necessary correction, the path planning point is imported into the main control program. Finally, the GPS navigation control system can control the unmanned agricultural machine to track the path along the planned path at a constant speed. . Figures 9 14 show the experimental results of linear path tracking, large-diameter circular path tracking and continuous small-diameter turning path tracking using the GPS navigation control system.

The data shows that when the unmanned agricultural machinery is working in a straight line, the speed is $0.5 \mathrm{~m} / \mathrm{s}$, the maximum error of agricultural machinery operation is 4.81 , and the average value is 2.59 . The latitude and longitude error data can be converted into distance data. The maximum error of agricultural machinery is $4.09 \mathrm{~cm}$, and the average error is $2.20 \mathrm{~cm}$, meeting the requirements of the path operation.

When the unmanned agricultural machinery is working on a large diameter circular path, the speed is $0.5 \mathrm{~m} / \mathrm{s}$, the maximum error of the agricultural machine operation is 24.32 , and the average value is 9.81 . The latitude and longitude error data can be converted into distance data, and the maximum error of the agricultural machine is $20.67 \mathrm{~cm}$. The error is $8.34 \mathrm{~cm}$, which meets the requirements of this path.

When the unmanned agricultural machinery is operating in a continuous small diameter turning path, the speed is $0.5 \mathrm{~m} / \mathrm{s}$, the maximum error of agricultural machinery operation is 27.22 , and the average value is 8.68 . The latitude and longitude error data can be converted into distance data, and the maximum error of agricultural machinery is $23.14 \mathrm{~cm}$. The error is $7.38 \mathrm{~cm}$, which satisfies the requirements of this path.

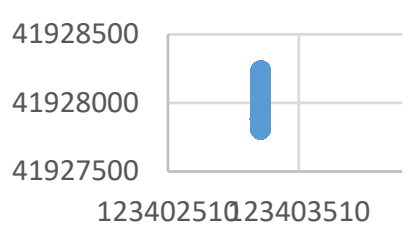

Fig. 9. Actual straight path tracking diagram.

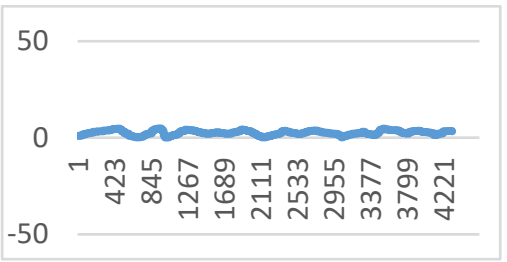

Fig. 10. Actual straight path tracking error curve. 


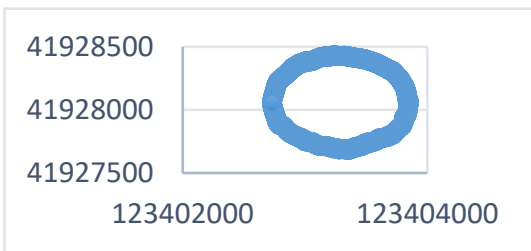

Fig. 11. Actual large diameter circular path tracking diagram.

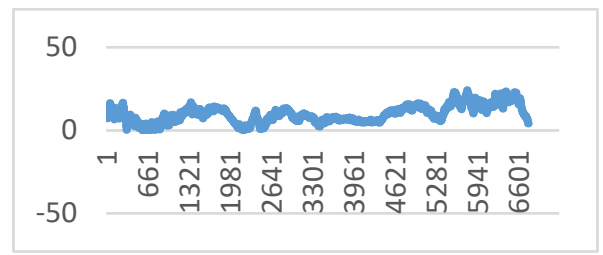

Fig. 12. Actual large diameter circular path tracking error curve.

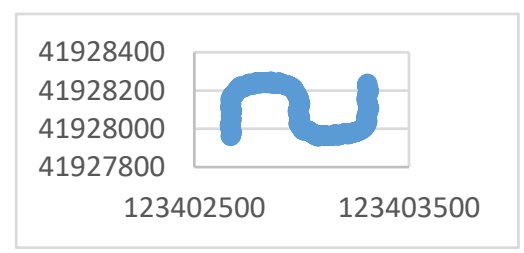

Fig. 13. Actual continuous small diameter turning path tracking diagram.

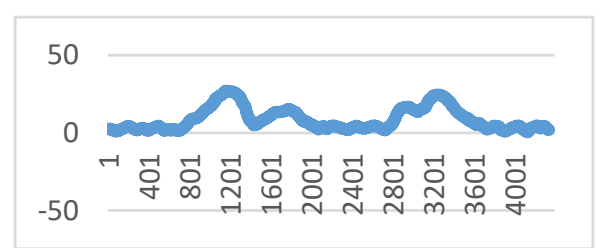

Fig. 14. Tracking error curve of actual continuous small diameter turning path.

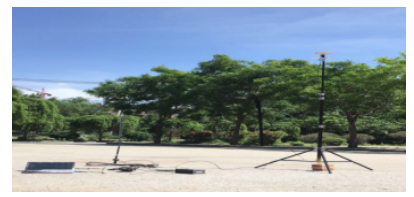

Fig. 15. RTK-GPS base station physical map.

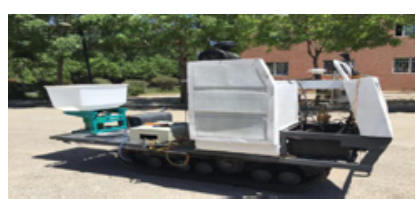

Fig. 16. Tractor body diagram.

\section{Conclusion}

In this paper, based on the requirements of "precision agriculture", an unmanned agricultural machinery control system is studied. The system uses incremental PID and fuzzy PID control algorithm to jointly control the throttle and gear size of the car body, and 
achieve centimeter-level positioning accuracy through differential GPS. Through the electronically controlled hydraulic steering system, the steering of the agricultural vehicle body is realized, which effectively alleviates the problem of lack of agricultural labor and effectively improves the accuracy of agricultural operations.

In the test, there is a case where the navigation accuracy is degraded when the occlusion is large. The next step is to use GPS to cooperate with the IMU to reduce the navigation error of the vehicle body when the signal is unstable.

\section{References}

1. Pan Wei. Research on Precision Positioning System of Agricultural Machinery Based on RTK [D]. Zhejiang University, 2017.

2. Kim J H , Moon H C, Woo H J , et al. Auto-guidance system for tillage tractor [C]// International Conference on Control. IEEE, 2014.

3. Nagasaka Y, Saito H, Tamaki K, et al. An autonomous rice transplanter guided by global positioning system and inertial measurement unit [J]. Journal of Field Robotics, 2010, 26(6-7): 537-548.

4. Li Yongjian, Zhao Yixi, Huang Peikui et al. Tractor automatic navigation system based on DGPS and double closed loop control[J]. Transactions of the Chinese Society of Agricultural Machinery, 2017, 48(2): 11-19. DOI:10.6041/j.issn.10001298.2017.02.002.

5. LI Yong-jian, ZHAO Yi-xi, GAO Jun-wen, WU Xiao-peng, GUAN Wei.Agricultural automatic navigation system based on DGPS positioning and double closed-loop steering control[J].农业研究研究,2016,37(02):387-394.

6. Shi Yangjie, Pei Xiaobo, Wu Fei, Zhang Ruihong, Jin Yifu, Gong Junjie. Design and experiment of motorized Beidou agricultural machinery automatic driving system [J/OL]. Journal of Northeast Agricultural University: 1-2[2019-05-28].

7. Hu Jingtao, Gao Lei, Bai Xiaoping, Li Huichang, Liu Xiaoguang. Research progress in automatic navigation technology of agricultural machinery[J]. Transactions of the Chinese Society of Agricultural Engineering, 2015, 31(10): 1-10.

8. Alexey S. Matveev, Michael Hoy, Jayantha Katupitiya, Andrey V. Savkin. Nonlinear sliding mode control of an unmanned agricultural tractor in the presence of sliding and control saturation [J]. Robotics and Autonomous Systems, 2013, 61 (9) ).

9. Zhang Wei. Research on autonomous following control system of crawler-type agricultural mobile robot [D]. Zhejiang University of Technology, 2017.

10. WANG Quansheng,ZHANG Mingzhu,BAI Dongyang,YIN Yuxin,HAO Xiaoyang.Fuzzy Adaptive PID Control of Multi-Stage Hydraulic Mechanical Continuously Variable Transmission of Tractor[J].Journal of Mechanical Transmission,2016,40(12):23-26+37.

11. Duan Xianqiang, Tao Jianfeng, Pei Chengjin, Cai Daoqing, Li Yanming, Liu Chengliang. Method of path tracking stability control for agricultural machinery under variable speed conditions [J/OL]. Journal of Agricultural Machinery: 1-10.

12. Xiong Zhonggang, Ye Zhenhuan, He Juan, Chen Liangui, Ling Hujinqing. Intelligent Tracking Control of Small Agricultural Machinery Path Based on Immune Fuzzy PID[J].Robots,2015,37,(02):212-223. 